\title{
Brote por Klebsiella pneumoniae multiresistente y productora de $\beta$-lactamasa de espectro extendido en una unidad de alto riesgo neonatal
}

\author{
A. Carolina González R., Florimar Gil G., Marisé Solórzano R., Jhon Cruz G., \\ Juan Puig P., Marlene Suárez S. y Beatriz Nieves B.
}

\begin{abstract}
Universidad de Los Andes,
Mérida, Venezuela

Facultad de Farmacia y Bioanálisis

Departamento de Microbiología y

Parasitología

Laboratorio de Investigaciones en Bacteriología "Roberto Gabaldón"

(ACGR, FGG, BNB).

Laboratorio de Biomedicina Experimental (LABIOMEX) (MSR,

JCG, JPP).

Hospital Universitario de Los

Andes, Mérida, Venezuela

Unidad de Alto Riesgo Neonatal

(MSS).
\end{abstract}

Recibido: 20 de agosto de 2009 Aceptado: 22 de dicimbre de 2010

Correspondencia a: Ana Carolina González Romero anagonzalezr@ula.ve

\section{Introducción}

L a infección nosocomial representa un desafío creciente en las unidades de neonatología que, lejos de haber sido solucionado, ha ido aumentando y haciéndose más complejo. Por un lado, cada vez se atienden niños con mayor grado de prematurez que son especialmente vulnerables a los microorganismos, y por otro lado, se utilizan procedimientos tecnológicos avanzados que son en muchas ocasiones, nuevas fuentes de entrada para las infecciones, siendo ello causa importante de la alta frecuencia de morbilidad y mortalidad en las unidades de cuidados intensivos neonatales (UCIN) ${ }^{1}$.

La septicemia neonatal es todavía una causa importante de morbilidad y mortalidad, a pesar del uso de terapias enérgicas y antimicrobianos de amplio espectro ${ }^{2}$. Como factores de riesgo para adquirir sepsis nosocomial se han descrito, además de la estancia hospitalaria prolongada, la multi-invasión con catéteres centrales venosos y arteriales, las múltiples punciones para obtener muestras de sangre, la administración de nutrición parenteral y la colocación de sondas oro-gástricas y naso-gástricas, los cuales constituyen las puertas de entrada más frecuentes de la infección ${ }^{3}$.

Otros factores ambientales que aumentan, de manera destacada el riesgo de infección, son: el hacinamiento en las cunas, el uso exagerado de antimicrobianos de amplio espectro y, en especial, las manos del personal como el vehículo más importante para transportar los microorganismos que participan en la génesis de una infección nosocomial ${ }^{4}$. Aparte de esta serie de factores que contribuyen a aumentar el riesgo de infecciones en neonatos, la literatura médica es consistente en señalar dos situaciones como las más importantes en el neonato: el bajo peso al nacer y la corta edad gestacional ${ }^{5}$.

Entre los microorganismos comúnmente involucrados en la sepsis nosocomial se encuentran los bacilos gramnegativos de la familia Enterobacteriaceae, especialmente especies del género Klebsiella ${ }^{6}$. Muchos de los brotes de infección nosocomial se deben a la diseminación de cepas resistentes a $\beta$-lactámicos, resistencia mediada por enzimas productoras de $\beta$-lactamasas de espectro extendido ( $\beta$ LEE) que son transportadas en plásmidos ${ }^{7}$. La gravedad de estas infecciones se incrementa si la cepas implicadas son multi-resistentes a antimicrobianos ${ }^{1}$.

En la unidad de alto riesgo neonatal (UARN) del Instituto Autónomo Hospital Universitario de los Andes (IAHULA), Estado de Mérida, se han realizado diversos estudios con la finalidad de conocer la frecuencia de las infecciones nosocomiales, así como, las características clínicas, microbiológicas y epidemiológicas de los brotes ocurridos en esta unidad. 
En abril-junio de 1998 ocurrió un brote de sepsis nosocomial por K. pneumoniae en los neonatos internados en dicha unidad. Las cepas aisladas en septicemia en los neonatos con bajo peso al nacer y prematuros, como así también en muestras de nutrición parenteral, eran productoras de $\beta$ LEE. Los datos de antibiotipia y de detección de $\beta$ LEE, sugirieron que los neonatos estaban infectados por un mismo antibiotipo de $K$. pneumoniae, lo que hizo presumir que la portación de $K$. pneumoniae en las manos del personal que manipuló a los pacientes y preparó las soluciones parenterales jugó un papel importante en la transmisión de la bacteria ${ }^{8}$.

Los estudios moleculares revelaron que estas cepas contenían un plásmido en el cual se localizaban genes que codificaban para una $\beta$ LEE tipo SHV-5 y una TEM- ${ }^{9}$. Posteriormente Rivera y $\operatorname{cols}^{10}$, tipificaron microbiológicamente las cepas de K. pneumoniae implicadas en el brote ocurrido en 1998, así como una cepa de $K$. pneumoniae aislada de un neonato con infección nosocomial durante el año 2002. Los resultados obtenidos permitieron establecer una relación epidemiológica entre el nuevo aislado y las cepas recuperadas durante el brote, sugiriendo la probable permanencia de K. pneumoniae en el área hospitalaria, quizás debido a fallas en la aplicación de medidas de control de la infección en la UARN. En otro trabajo, llevado a cabo en la misma unidad clínica por Barrera y cols ${ }^{11}$, se caracterizaron cepas aisladas entre los meses octubre y diciembre del 2002, mediante pruebas de susceptibilidad antimicrobiana y la reacción en cadena de la polimerasa de elementos palindrómicos extragénicos repetitivos (REP- PCR), comprobándose la existencia de un clon de $K$. pneumoniae durante dicho período, diferente al genotipo involucrado en el brote de septicemia nosocomial ocurrido entre abril-junio 1998.

El presente trabajo se realizó con el fin de determinar las características microbiológicas y genotípicas de $K$. pneumoniae multi-resistente, productora de $\beta \mathrm{LEE}$, asociada a un brote de sepsis neonatal ocurrido en la UARN del IAHULA Mérida Venezuela, durante finales del mes de febrero de 2007. Así mismo se estudiaron cepas de $K$. pneumoniae aisladas con posterioridad al brote y cepas aisladas del ambiente y del personal como posible fuente de la infección.

\section{Pacientes y Métodos}

Población en estudio. Se evaluó una muestra representativa de 321 neonatos hospitalizados en la UARN del IAHULA, durante el período comprendido entre el 3 de febrero 2007 y el 30 de junio del mismo año. Los datos clínicos y epidemiológicos de los neonatos se registraron en una ficha destinada para tal fin. Como factores predisponentes se consideraron los siguientes: bajo peso al nacer, prematurez, procedimientos invasores y antibioterapia previa. Ente los factores maternos se tomaron en cuenta: ruptura prematura de membranas, corio-amnionitis e infección urinaria

Criterios de inclusión: Neonatos con sospecha de sepsis, documentado por cuadro clínico (taquicardia, bradicardia, taquipnea, fases de apnea, sintomatología digestiva -intolerancia digestiva, vómitos, distensión abdominal, etc-y sintomatología neurológica-depresión neurológica, irritabilidad, convulsiones-) y exámenes de laboratorio: (hemograma con signos de infección y proteína $\mathrm{C}$ reactiva $>10 \mathrm{mg} / \mathrm{L}$ ). En segundo lugar, tener un período mayor a 48 horas de haber ingresado a la unidad.

Criterios de exclusión: Neonatos con otra patología diferente a sepsis y tener un período menor a 48 horas de haber ingresado a la unidad.

Descripción del brote. En el mes de febrero del 2007 ocurrió un aumento en la incidencia de sepsis documentado clínicamente y por el aislamiento de K. pneumoniae multi-resistente productora de $\beta \mathrm{LEE}$ en los neonatos hospitalizados en la UARN del IAHULA. El hospital es de tipo IV, está dotado con un total de 780 camas y 50 cunas en el área neonatal. Siendo éste es el único servicio de neonatología público, recibe pacientes de la región de Los Andes y también de sus alrededores, parte de los estados de Barinas, Zulia y Táchira, presentándose hacinamiento por sobrepoblación pues atiende diariamente entre 70-80 pacientes. El brote ocurrió en un período de 10 días, entre el 27 de febrero y el 8 de marzo, durante el cual, se aisló un total de cinco cepas de $K$. pneumoniae multi-resistentes a partir de la sangre de cinco neonatos internados en la misma sala (período epidémico).

La tasa habitual de aislamiento de esta bacteria en la unidad es baja, pero periódicamente ocasiona brotes, como se ha reportado en estudios anteriores realizados en esta unidad ${ }^{8,11}$. Lamentablemente no se cuenta con los datos del período pre-epidémico, correspondientes al año 2006. Con posterioridad, entre los meses de mayo y junio del 2007 (período post epidémico) se aisló 8 cepas de $K$. pneumoniae multi-resistentes en sangre de otros pacientes.

Además, durante el período del brote se realizó un muestreo microbiológico para determinar la posible fuente de infección. Para ello se obtuvo muestras de las manos en el personal que laboran en la mencionada unidad en los turnos de la mañana y tarde, sin previo aviso. También se realizó un muestreo microbiológico ambiental de algunas áreas de la UARN.

El estudio fue aprobado por las instancias del IAHULA involucradas, y no requirió procedimientos clínicos distintos a los realizados habitualmente en la atención de los pacientes. El procesamiento de las muestras se llevó a cabo en el Laboratorio de Bacteriología "Dr. 
Roberto Gabaldón”, Departamento de Microbiología y Parasitología de la Facultad de Farmacia y Bioanálisis de la Universidad de Los Andes.

\section{Estudio bacteriológico de las muestras}

Cultivos: A todos los neonatos con sospecha clínica de sepsis se les realizó el estudio microbiológico de las muestras de sangre y, en algunos casos, de otros sitios tales como LCR, siguiendo la metodología convencional, y de puntas de catéter por técnica de Maki.

Colonización del personal de salud. Para determinar la colonización de las manos del personal se obtuvieron muestras mediante la impresión de los dedos pulgar, índice y medio en placas de agar tripticasa soya con lecitina y Tween 80 (TSLT) (HIMEDIA Laboratories Limited, India) y en agar MacConkey (MK) (HIMEDIA Laboratories Limited, India). Los medios se incubaron a $37{ }^{\circ} \mathrm{C}$ durante 48 horas.

Muestreo microbiológico ambiental. Para determinar la contaminación de algunas áreas de la UARN se tomaron 33 muestras provenientes de las soluciones para hidratación parenteral que estaban siendo administradas a los neonatos, de la campana de flujo laminar (CFL) donde se preparan tales soluciones y también de las soluciones jabonosas. La presencia de microorganismos en fuentes líquidas (soluciones parenterales y jabonosas) se determinó al colocar una muestra de 1-5 ml de cada solución en tubos estériles. Luego las muestras se inocularon en caldo BHI, agar MK y TSLT y se incubaron a $37{ }^{\circ} \mathrm{C}$ durante 48 horas.

Identificación de los microorganismos aislados. Para estos efectos se siguieron los procedimientos descritos por Koneman y cols ${ }^{12}$.

Susceptibilidad antimicrobiana de los microorganismos aislados. Se determinó la susceptibilidad a los agentes antimicrobianos, sobre agar Mueller Hinton (MH) (HIMEDIA Laboratories Limited, India) por el método de difusión del disco, de acuerdo a las instrucciones del CLSI $2006^{13}$. La CIM de ceftazidima y cefotaxima (Distriquimica S.A) ante las cepas de $K$. pneumoniae se realizó siguiendo las instrucciones del $\mathrm{CLSI}^{10}$, utilizando como punto de corte para determinar la sensibilidad, CIM $\leq 2 \mu \mathrm{g} / \mathrm{ml}$ y probando por duplicado concentraciones seriadas y al doble de los mencionados antimicrobianos $(0,004-128 \mu \mathrm{g} / \mathrm{ml})$.

Detección de $\beta L E E$ en las cepas de K. pneumoniae aisladas. A las cepas de $K$. pneumoniae resistentes a cefalosporinas de tercera generación se les examinó la producción de $\beta$ LEE mediante el método descrito por Pitout et $\mathrm{al}^{14}$.

Detección de los genes TEM y SHV en las cepas de K. pneumoniae mediante RPC. La extracción de ADN se realizó por calentamiento a $90^{\circ} \mathrm{C}$.

La secuencia del iniciador TEM 1 fue: (5'-ATA AAA
TTC TTC TTG AAG ACG AAA 3') y TEM 2 (5' GAC AGT TAC CAA TGC TTA ATC A 3') (Invitrogen). La secuencia del iniciador SHV1 fue: (5'-TCA GCG AAA AAC ACC TTG 3') y SHV2 (5'TCC CGC AGA TAA ATC ACC A 3') (Invitrogen). Se incluyó un control negativo con una mezcla de todos los componentes de la mezcla de reacción, excepto el ADN, y como control positivo se utilizó una cepa de $K$. pneumoniae productora de $\beta$ LEE tipo TEM y SHV caracterizada previamente. El programa de amplificación para TEM se realizó bajo las siguientes condiciones: temperatura de desnaturalización inicial: $94{ }^{\circ} \mathrm{C}$ durante 5 minutos, 35 ciclos de $94{ }^{\circ} \mathrm{C} 1$ minuto, $50{ }^{\circ} \mathrm{C} 1$ minuto, $72{ }^{\circ} \mathrm{C} 1$ minuto. En el caso de la amplificación correspondiente a SHV el programa fue: temperatura de desnaturalización inicial: $94^{\circ} \mathrm{C}$ durante 2 minutos, 35 ciclos de $94{ }^{\circ} \mathrm{C} 1$ minuto, $66^{\circ} \mathrm{C} 1$ minuto, $72{ }^{\circ} \mathrm{C} 30$ segundos y una temperatura final de extensión de $72{ }^{\circ} \mathrm{C}$ durante 5 minutos.

Relación clonal entre los diferentes aislados mediante RPC de elementos repetitivos (REP-PCR). La extracción de ADN cromosomal se realizó mediante el método descrito por Snelling y cols ${ }^{15}$. Los oligonucleotidos utilizados se basan en elementos palindrómicos extragénicos repetitivos de ADN altamente conservados, cuya secuencia es la siguiente: REP-1 (5'-III ICGICGICATCIGGC-3'); REP-2 (5'-ICGICTTATCIGGCCTAC-3') (Bio. Synthesis) Versalovic y cols ${ }^{16}$. La amplificación se realizó en un termociclador Cycler (Bio-Rad), el cual fue programado para una temperatura de desnaturalización inicial de 95 ${ }^{\circ} \mathrm{C}$ durante 5 minutos, seguidos por 4 ciclos de desnaturalización de: $94{ }^{\circ} \mathrm{C}$ durante 1 min, unión: $26{ }^{\circ} \mathrm{C}$ por $1 \mathrm{~min}$, extensión: $72^{\circ} \mathrm{C}$ por $2 \mathrm{~min}$. Luego por 40 ciclos de desnaturalización del ADN blanco $\left(94^{\circ} \mathrm{C}\right.$ durante 5 min), unión de los oligonucleótidos al ADN blanco $\left(40^{\circ} \mathrm{C}\right.$ durante 30 segundos) y extensión de los mismos unidos al $\mathrm{ADN}\left(72^{\circ} \mathrm{C}\right.$ durante $\left.1 \mathrm{~min}\right)$, una temperatura final de extensión $\left(72{ }^{\circ} \mathrm{C}\right.$ durante $\left.10 \mathrm{~min}\right) . \mathrm{El}$ ensayo se realizó tres veces obteniéndose los mismos resultados.

Análisis estadístico. Se utilizó el paquete estadístico SPSS. Versión 9.0 para Windows, aplicando el test de independencia basado en distribución de $\chi^{2}$, tomando en cuenta un valor de $\mathrm{p} \leq 0,05$ para evaluar la significancia de las variables relacionadas.

\section{Resultados}

Se incluyeron todos los neonatos con sospecha de sepsis según criterio de su médico tratante (n: 321), a los que se cultivó muestras de: sangre (n: 276), LCR (n: 42) y extremo distal de catéter venoso (n: 3 ).

En 39 pacientes se precisó el diagnóstico etiológico, 
mediante 38 aislados de sangre: K. pneumoniae (n: 13), Staphylococcus coagulasa negativa (n: 8), Acinetobacter sp (n: 7), Pseudomonas sp (n: 5), Candida albicans (n: 3), Pseudomonas aeruginosa (n: 2), y un aislado en LCR: Steptococcus sp. De las 42 muestras de LCR estudiadas, sólo una dio cultivo positivo. No hubo cultivos positivos a partir de los catéteres endovenosos extraídos.

Cinco de las 13 cepas de $K$. pneumoniae fueron aisladas durante el período epidémico.

Los 321 neonatos recibieron terapia antimicrobiana empírica inicial, la que se ajustó según se conocieron los datos microbiológicos. La combinación de $\beta$-lactámicos con aminoglucósidos fue el tratamiento inicial empleado en $92,3 \%$ (n: 36 ) de los pacientes con infección confirmada. En el resto se empleó la combinación de $\beta$-lactámicos más aminoglucósidos más fluconazol.

Los principales factores de riesgo asociados a sepsis fueron: antibioterapia previa $(92,6 \%)$, procedimientos invasores $(92,6 \%)$, prematurez $(90,2 \%)$ y bajo peso al nacer $(87,8 \%)$, Al aplicar la prueba de independencia basada en la distribución de $\chi^{2}$, se encontró una asocia- ción estadísticamente significativa entre la presencia de $K$. pneumoniae y la prematurez $\left(\chi^{2}=56,809\right)$, bajo peso al nacer $\left(\chi^{2}=38,905\right)$ y antibioterapia previa $\left(\chi^{2}=\right.$ $391,902)$, pero no con el uso de procedimientos invasores $\left(\chi^{2}=6,199\right)$.

Entre las condiciones prenatales anormales, las infecciones urinarias maternas se presentaron en $51,2 \%$. No se encontró relación estadísticamente significativa entre la presencia de $K$. pneumoniae y las condiciones maternas $\left(\chi^{2}=25,132\right)$.

A mediados del mes de febrero se había aislado cepas de K. pneumoniae, en forma consecutiva de cinco neonatos internados en el mismo ambiente, por lo que se decidió realizar un muestreo microbiológico ambiental, incluyendo el personal de salud, con la finalidad de encontrar la fuente de infección.

De las 25 muestras obtenidas de las manos del personal que laboraba en la unidad, en los turnos de mañana y tarde, en $5(20 \%)$ se aisló cepas multi-resistentes de $K$. pneumoniae.

En el ambiente inanimado se aisló cepas de K. pneu-

Tabla 1. Características de las cepas de $K$. pneumonie aisladas de los recién nacidos con sepsis nosocomial y del medio ambiente

\begin{tabular}{|c|c|c|c|c|c|c|c|c|}
\hline $\begin{array}{l}\text { Cepa n de } \\
\text { laboratorio }\end{array}$ & $\begin{array}{l}\text { Fecha toma } \\
\text { de muestra }\end{array}$ & Sala & $\begin{array}{c}\text { Fenotipo de } \\
\beta L E E\end{array}$ & $\begin{array}{c}\text { Tipo de } \\
\text { BLEE }\end{array}$ & $\begin{array}{c}\text { CIM CAZ } \\
(\mu \mathrm{g} / \mathrm{ml})\end{array}$ & $\begin{array}{c}\text { CIM CTX } \\
(\mu \mathrm{g} / \mathrm{ml})\end{array}$ & Antibiotipo & Genotipo \\
\hline 1. $18 \mathrm{RN}$ & $18 / 02 / 2007$ & UCIT (A) & + & TEM y SHV & 128 & 64 & 1 & 1 \\
\hline 2. $20 \mathrm{RN}$ & $19 / 02 / 2007$ & UCIT (A) & + & TEM y SHV & 128 & 64 & 1 & 1 \\
\hline 3. $21 \mathrm{RN}$ & 19/02/2007 & UCIT (A) & + & TEM y SHV & 128 & 64 & 1 & 1 \\
\hline 4. $22 \mathrm{RN}$ & $19 / 02 / 2007$ & UCIT (A) & + & TEM y SHV & 128 & 64 & 1 & 1 \\
\hline 5. $23 \mathrm{RN}$ & $21 / 02 / 2007$ & UCIT (A) & + & TEM y SHV & 128 & 64 & 1 & 1 \\
\hline 6. $M$ & $27 / 02 / 2007$ & UCIT (A) & + & TEM y SHV & 128 & 64 & 1 & 1 \\
\hline 7. JG & $27 / 02 / 2007$ & Depósito & + & TEM y SHV & 128 & 64 & 1 & 1 \\
\hline 8. JT & $27 / 02 / 2007$ & UCIT (A) & + & TEM y SHV & 128 & 64 & 1 & 1 \\
\hline 9. JA & $27 / 02 / 2007$ & UCIT (B) & + & TEM y SHV & 128 & 64 & 1 & 1 \\
\hline 10. JB & $27 / 02 / 2007$ & $\mathrm{UCl}$ & + & TEM y SHV & 128 & 64 & 1 & 1 \\
\hline 11. ML & $27 / 02 / 2007$ & Depósito & + & TEM y SHV & 128 & 64 & 1 & 1 \\
\hline 12. $188 \mathrm{RN}$ & 06/04/2007 & UCIT (A) & - & TEM y SHV & 32 & 64 & 1 & 2 \\
\hline 13. $189 \mathrm{RN}$ & $07 / 04 / 2007$ & UCIT (A) & - & TEM y SHV & 32 & 64 & 2 & 2 \\
\hline 14. $195 \mathrm{RN}$ & 09/04/2007 & UCl & + & TEM y SHV & 64 & 128 & 2 & 3 \\
\hline 15. $198 \mathrm{RN}$ & $11 / 04 / 2007$ & UCIT (A) & + & TEM y SHV & 64 & 128 & 2 & 4 \\
\hline 16. $231 \mathrm{RN}$ & $16 / 04 / 2007$ & UCIT (A) & - & TEM y SHV & 32 & 128 & 1 & 5 \\
\hline 17. $232 \mathrm{RN}$ & $16 / 04 / 2007$ & UCIT (A) & - & TEM y SHV & 32 & 128 & 2 & 5 \\
\hline 18. $236 \mathrm{RN}$ & $22 / 04 / 2007$ & $\mathrm{UCl}$ & - & TEM y SHV & 32 & 256 & 2 & 6 \\
\hline 19. $263 \mathrm{RN}$ & $15 / 05 / 2007$ & UCIT (B) & - & TEM y SHV & 32 & 128 & 1 & 7 \\
\hline
\end{tabular}




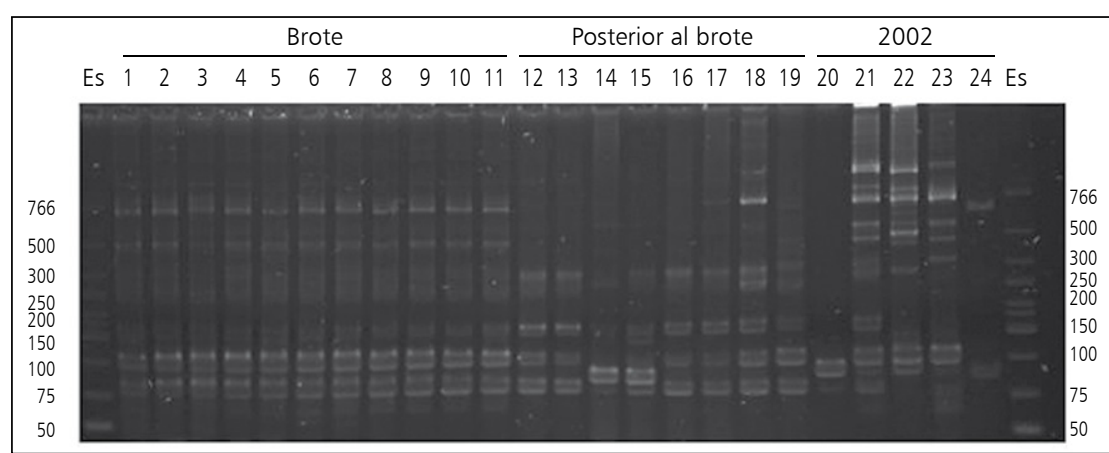

Figura 1. Patrón de bandas obtenidas por REP-PCR de las cepas de $K$. pneumoniae aisladas de la UARN del IAHULA. Esc: escalera de bajo peso molecular New England Biolabs. Línea 1-11 (genotipo 1): cepas de $K$. pneumoniae aisladas de la sangre de los recién nacidos de las soluciones jabonosas manos y manilla del lavamanos durante el brote. Línea 12-13 (genotipo 2). Línea 14-15 (genotipos 3 y 4), Línea 16-17 (genotipos 5), Línea 18-19 (genotipos 6 y 7) cepas de K. pneumoniae aisladas de la sangre de los recién nacidos meses después del brote. Línea 20-23 (genotipos 8,9,10,11) cepas aisladas durante el año 2002 Línea 24 control negativo, mezcla de todos los componentes anteriormente citados, excepto el ADN. Línea 25 (nuevamente la escalera de bajo peso molecula New England Biolabs). moniae multi-resistente de las tres soluciones jabonosas en uso y en la solución jabonosa del depósito. De igual manera, se aisló una cepa de $K$. pneumoniae de la manilla de uno de los lavamanos.

Patrón de susceptibilidad in vitro de K. pneumoniae. El antibiotipo resistente a cefalosporinas de tercera generación, la combinación de $\beta$-lactámicos/inhibidores de $\beta$-lactamasas y aminoglucósidos fue detectado en $61,5 \%$ (n: 8) de los casos, tanto en las cepas aisladas de los neonatos durante el brote, como de las soluciones jabonosas, manilla de lavamanos y manos de una camarera encargada de mantener limpia el área de neonatología (pisos, lavamanos, mesas, paredes) y de colocar las soluciones jabonosas en los dispensadores de jabón (Tabla 1).

La CIM de ceftazidima y cefotaxima para las cepas aisladas de los neonatos durante el brote y posteriores a éste, así como las aisladas durante el estudio ambiental durante el período epidémico fue $\geq 128 \mu \mathrm{g} / \mathrm{ml}$ y $64 \mu \mathrm{g} /$ $\mathrm{ml}$, respectivamente. Además las cepas aisladas durante el brote y del estudio ambiental resultaron productoras de $\beta$ LEE y portaban los genes $b l a_{\mathrm{SHV}}$ y $b l a_{\mathrm{TEM}}$. En cambio, las cepas aisladas con posterioridad a éste no mostraron fenotipo $\beta \operatorname{LEE}(+)$ excepto dos cepas aisladas durante el mes de abril, pero todas portaban los genes $b l a_{\text {SHV }}$ y bla $_{\text {TEM }}$ (Tabla 1.)

Mediante REP-PCR se comprobó que las cepas de $K$. pneumoniae, aisladas de las muestra de sangre de los neonatos durante el brote, así como de las soluciones jabonosas, manilla de lavamanos y manos de una camarera presentaban el mismo patrón de bandas: genotipo 1 (Tabla 1). Pero aquellas aisladas después del brote no mostraron relación clonal con las del período epidémico. Sin embargo, se puede observar que entre ellas, algunas mostraron patrones de bandas similares: los genotipos 2 y 5 (Figura 1).

Se comparó los clones de este brote con uno anterior ocurrido en el año 2002 en la misma unidad -4 cepas del 2002-, con la finalidad de detectar si los clones del 2002 aún permanecían en el ambiente, observándose que no hubo relación clonal entre ellas (Figura 1).

\section{Discusión}

Klebsiella pneumoniae fue el patógeno mayormente implicado en la etiología de la sepsis neonatal en la UARN del IAHULA durante este estudio, resultado similar a lo descrito en otras unidades de neonatología en países de América Latina, donde aproximadamente $60 \%$ de las sepsis neonatales son causadas por bacilos gramnegativos, entre ellos, K. pneumoniae ${ }^{8}$. En una investigación anterior realizada en nuestra institución, $K$. pneumoniae se aisló de la sangre de los neonatos y de las soluciones parenterales suministradas a los recién nacidos en 46 y $61 \%$, respectivamente ${ }^{11}$.

A pesar de las medidas de control y prevención de las infecciones nosocomiales implementadas en la UARN, la tasa de aislamiento de esta bacteria se incrementa cuando hay hacinamiento, por lo que periódicamente ocasiona brotes, tal como ocurrió a finales del mes febrero del año 2007, cuando fueron afectados cinco neonatos hospitalizados en el mismo ambiente en un período de diez días.

Los neonatos infectados con K. pneumoniae durante el brote y posteriormente a éste eran prematuros, con bajo peso al nacer y con tratamiento previo con $\beta$-lactámicos y aminoglucósidos, principales factores de riesgo que favorecen las infecciones nosocomiales en este grupo de pacientes; no se encontró relación estadísticamente significativa con el antecedente de procedimientos invasores.

Por otra parte, es preocupante el grado de resistencia antimicrobiana observado en las cepas de K. pneumoniae aisladas a los antimicrobianos con los que se cuenta en la UARN. Klebsiella pneumoniae fue resistente a ocho agentes antimicrobianos, especialmente a $\beta$-lactámicos $(100 \%)$, la combinación de $\beta$-lactámicos/inhibidores de $\beta$-lactamasas (100\%), monobactámicos $(100 \%)$ y aminoglucósidos (amikacina 100\% y gentamicina 76,9\%), conservando sensibilidad a carbapenémicos, cefamicinas y quinolonas.

Las cepas de $K$. pneumoniae aisladas de los neonatos y de las soluciones parenterales, en estudios anteriores realizados en la misma unidad ${ }^{8,11}$ tenían menor porcentaje de resistencia a antimicrobianos, en particular a la combinación de $\beta$-lactámicos/inhibidores de $\beta$-lactamasas pero similares a cefalosporinas de tercera generación y 
amikacina ${ }^{17}$. Igualmente, la resistencia a gentamicina se incrementó desde 0 hasta $76,9 \%$ en el presente estudio.

Se encontraron dos perfiles de resistencia antimicrobiana: el antibiotipo 1 resistente a cefalosporinas de tercera generación, la combinación $\beta$-lactámicos/inhibidores de $\beta$-lactamasas y aminoglucósidos y sensibles a imipenem, cefoxitin y ciprofloxacina -el más frecuente- abarcó 8 cepas, 5 aisladas de los neonatos durante el brote y 3 aisladas a posteriori. Este antibiotipo también fue aislado de las soluciones jabonosas, de la manilla del lavamanos y de las manos de una camarera. Todas las cepas de $K$. pneumoniae de este perfil mostraron el fenotipo $\beta \operatorname{LEE}(+)$ y la CIM de ceftazidima y cefotaxima también fue similar (superior al valor de corte de sensibilidad).

En cuanto al antibiotipo 2, las cepas presentaron resistencia a las cefalosporinas de tercera generación, $\beta$-lactámicos/inhibidores de $\beta$-lactamasas y amikacina y sensibilidad a gentamicina, imipenem, cefoxitin y ciprofloxacina. A diferencia del antibiotipo 1, el 2 resultó sensible a gentamicina.

Estos hallazgos revelan la estrecha relación epidemiológica y microbiológica de las cepas, resultado que fue corroborado mediante REP-PCR, a través del cual se pudo identificar a un clon (genotipo 1) como el responsable de la infección causada en los RN, presente además, en las manos de una camarera y cuya posible fuente fueron las soluciones jabonosas en uso y las que se encontraban en el depósito. Es importante destacar que estos resultados deben ser confirmados a través de métodos más específicos para el estudio clonal como la electroforesis en gel de campo pulsado.

Todos los aislados obtenidos durante y con posterioridad al brote expresaron dos tipos de $\beta$ LEE, TEM y la SHV. Cepas de K. pneumoniae aisladas en algunos hospitales de Latinoamérica producen con relativa frecuencia este tipo de $\beta \mathrm{LEE}^{17-19}$. De manera similar, en Europa y E.U.A., se le ha atribuido a $K$. pneumoniae productora de $\beta$ LEE, SHV y TEM hasta el $50 \%$ de los brotes causados por dicho microorganismo ${ }^{20}$. En España en los últimos años, se ha reportado la prevalencia de cepas productoras de $\beta$ LEE en determinadas áreas y se han comunicado diversos brotes hospitalarios, donde se detecta con mayor frecuencia distintos tipos de CTX-M $\mathrm{M}^{20,21}$. Estas enzimas también se han reportado en Argentina, Brasil y recientemente en Colombia, asociadas a numerosos brotes epidémicos causados por K. pneumoniae ${ }^{22-24}$.

El tratamiento oportuno de los neonatos con imipenem contribuyó a controlar el brote, las cepas de K. pneumoniae aisladas eran resistentes a ampicilina/sulbactam, piperacilina/tazobactam, cefotaxima, amikacina y gentamicina, antimicrobianos que se les estaba suministrando a los neonatos como terapia inicial. Los carbapenémicos aún permanecen $100 \%$ activos contra las cepas productoras de $\beta \mathrm{LEE}$ aisladas de la UARN; no obstante, su uso debe vigilarse permanentemente, por cuanto su utilización indiscriminada podría originar la selección de cepas de bacilos gramnegativos no fermentadores resistentes.

Agradecimiento. Al Consejo de Desarrollo Científico Humanístico y Tecnológico (CDCHT). Proyecto código: (FA- 414-07-07-B) por la financiación del estudio. De igual manera, a los pacientes y al personal de la Unidad de Alto Riesgo Neonatal del IAHULA.

\section{Resumen}

Klebsiella pneumoniae productora de $\beta$-lactamasa de espectro expandido ( $\beta \mathrm{LEE}$ ) ha jugado un papel importante como causa de infecciones en la unidad de alto riesgo neonatal (UARN) del Instituto Autónomo Hospital Universitario de Los Andes (IAHULA). En el presente trabajo se describe un brote ocasionado por esta bacteria en los neonatos hospitalizados en dicha unidad durante el mes de febrero 2007, así como también, cepas aisladas en los meses siguientes al brote y además, se estudia el ambiente y el personal, como posible fuente de esta bacteria. Las cepas de $K$. pneumoniae aisladas del brote eran del mismo fenotipo de resistencia, productoras de $\beta$ LEE tipo TEM y SHV y pertenecían al mismo genotipo que las cepas aisladas de las manos y de las soluciones jabonosas, posible fuente de infección, lo cual indica que se trataba del mismo clon. El brote se resolvió usando dos importantes medidas: reforzando el lavado de manos y con la indicación oportuna de imipenem a los neonatos afectados.

\section{Referencias}

1.- Orfali J. Sepsis neonatal. Nuevas estrategias terapéuticas. Rev Ped Elect 2004; 1 (1): 25-31.

2.- Cifuentes Y, Ruiz A, Leal A, Muñoz L, Herrera M, Jiménez L. Perfil microbiologico de aislamientos en unidades neonatales en un hospital de tercer nivel de Bogotá, Colombia. Rev Salud Pública 2005; 72 (2): 191-200.

3.- Silva N, Oliveira M, Bandeira A, Brites C. Risk factors for infection by extended-spectrum betalactamase producing Klebsiella pneumoniae in a tertiary hospital in Salvador. J Infect Dis 2006; 10 (3): 191-3.

4.- Vergnano S, Shaland M, Kazembe P, Musambo C, Heath P. Neonatal sepsis: an international perspective. Arch Dis Child Fetal Neonatal 2004; 90: 220-4.

5.- Osrin D, Vernagno S, Costello A. Serious bacterial infections in newborn infants in developing countries. Curr Opin Infect Dis 2004; 17: 217-24.

6.- Blomberg B, Jureen R, Manji K P, Tamim B S, Mwakegile D S, Urassa W K, et al. High rate of fatal cases of pediatric septicemia caused by gram-negative bacteria with extended- spectrum $\beta$-lactamases in Dar es Salaam Tanzania. J Clin Microbiol 2005; 43 (2): 745-9.

7.- Navon- Venezia S, Leavitt A, Ben-Ami R, Aharono Y, Schwartz M, Schwartz D, et al. 
Evaluation of an accelerated protocol for detection of extended- spectrum $\beta$-lactamaseproducing gram negative bacilli from positive blood cultures. J Clin Microbiol 2005; 43 (1): 439-41.

8.- Calderas Z, Nieves B, Araque M, Torres A, Mosqueda N. Klebsiella pneumoniae productora de $\beta$ LEE como agente etiológico de septicemia en una unidad de cuidados intensivos. Resumen de las XXVI Jornadas Venezolanas de Microbiología Dr. José Esparza "Infecciones Emergentes". Valencia noviembre 1999; p.33.

9.- Araque M, Nieves B, Lauretti L, Rossolini G. Molecular basis of extended-spectrum $\beta$-lactamase production in nosocomial isolates of Klebsiella pneumoniae from Mérida, Venezuela. Int J Antimicrob Agents 2000; 15: $37-42$.

10.- Rivera I. Tipificacición microbiológica como herramienta para el estudio epidemiológico de Klebsiella pneumoniae de origen nosocomial. Tesis Inédita de Especialista en Microbiología Clínica, Universidad de los Andes. 2002 Mérida-Venezuela.

11.- Barrera D, Sua L, Cestari Y. Caracterización de cepas de Klebsiella pneumoniae aisladas de neonatos con infección nosocomial en una unidad de alto riesgo. Tesis inédita para optar al título de Licenciadas en Bioanálisis, Universidad de los Andes, 2004. Mérida-Venezuela.

12.- Koneman E, Allen S, Janda W, Schreckenberger P, Winn W. Diagnóstico Microbiológico. Texto y atlas a color. 6ta ed. Buenos Aires Argentina, Médica Panamericana; 2007, p. 44-335.

13.- Clinical and Laboratory Standards Institute. Performance standards for antimicrobial susceptibility testing. 2006; $16^{\text {th }}$ informational supplement.

14.- Pitout J, Reisbig M, Venter E, Church D, Hanson M. Modification of the double-disk test for detection of Enterobacteriaceae producing extended-spectrum and AmpC $\beta$-lactamases. J Clin Microbiol 2003; 41 (8): 3933-5.

15.- Snelling A, Gerner P, Hawkey P, Heritage J, Parnel P, Poster C. Validation of use of whole-cell repetitive extragenic palindromic secuence based PCR (REP-PCR) for typing strains belonging to the Acinetobacter calcoaceticus-Acinetobacter baumannii complex and aplication of the method to the investigation of a hospital outbreak. J Clin Microbiol 1996; 34 (5): 1193-202.

16.- Versalovic J, Koeuth T, Lupsky J. Distribution of repetitive DNA sequentes in eubacteria and application to fingerprinting of bacteria genome. Nucleic Acids Res 1991; 19: 6823-31.

17.- Espinal P, Mantilla J, Saavedra C, Leal A, Alpuche C, Valenzuela E. Epidemiología molecular de infeccion nosocomial por Klebsiella pneumoniae productora de betalactamasas de espectro extendido. Biomed 2005; 24 (3): 252-61.

18.- Morales J, Reyes K, Monteghirfo M, Roque M, Irey J. Presencia de $\beta$-lactamasas de espectro extendido en dos hospitales de Lima, Perú. Ann Fac Med Lima 2006; 66 (1): 16-8.
19.- González L, Ramos A, Morffi J, Hernández E, Álvarez A, Marchena J, et al. Identificación fenotípica y molecular de beta lactamasas de espectro extendido TEM y SHV producidas por Escherichia coli y Klebsiella spp aislados clínicos en hospitales. Rev Cuba Med Trop 2007; 59 (1): 210-3.

20.- Muñoz J. Betalactamasas de espectro extendido: ¿Son hoy un serio problema en España? Rev Esp Quimioterap 2004; 14: 314-6.

21.- Casellas J, Nannini E, Radice M, Cocconi E, Lejona S, Borda N, et al. Estudio de un brote debido a aislados de Klebsiella pneumoniae productores de betalactamasas de espectro extendido en un centro asistencial de RosarioArgentina. Rev Panam Infectol 2005; 7 (4): 21-7.

22.- Vignoli R, Cordeiro N, Seija V, Schelotto F, Radice M, Ayala J, et al. Entorno genético de CTX-M-2 en aislamientos de Klebsiella pneumoniae provenientes de pacientes hospitalizados en Uruguay. Rev Argent Microbiol 2006; 38: 84-8.

23.- Minarini L A, Climaco E C, Guimaraes D B, Ferreira J C, Palazzo I C, Martínez R, et al. Clonal transmission of ESBL-producing Klebsiella spp at a university hospital in Brazil. Curr. Microbiol 2008; 56 (6): 587-91.

24.- Gupta A, Della-Latta P, Todd B, San Gabriel P, Haas J, Wu F, et al. Outbreak of extendedspectrum beta-lactamase-producing Klebsiella pneumoniae in a neonatal intensive care unit linked to artificial nails. Infect Control Hosp Epidemiol 2004; 25: 210-5. 